\title{
AN INTERESTING RARE CASE OF BENIGN CONGENITAL OESOPHAGO- BRONCHIAL FISTULA PRESENTING IN ADULTHOOD - A CASE REPORT
}

Narayan $\mathrm{M}^{1}$, Devershi Ajay Dilip ${ }^{2}$, Chandankhede Abhijit Ravindra ${ }^{3}$

\section{HOW TO CITE THIS ARTICLE:}

Narayan M, Devershi Ajay Dilip, Chandankhede Abhijit Ravindra. "An interesting rare case of benign congenital oesophago- bronchial fistula presenting in adulthood - a case report". Journal of Evolution of Medical and Dental Sciences 2013; Vol. 2, Issue 42, October 21; Page: 8141-8145.

ABSTRACT: Congenital broncho-oesophageal fistula is a rare entity in adult patients. This anomaly may cause various symptoms such as respiratory infections, coughing bouts when eating or drinking and even hemoptysis. Even rarer than its occurrence with the above-mentioned symptoms is its presentation with bronchiectasis. Here we report a rare case of a congenital broncho-oesophageal fistula presenting with bronchiectasis in a 20-year-old male, came to us with chronic productive cough and recurrent upper respiratory infections, diagnosed incidentally on upper GI endoscopy. The condition was later confirmed on bronchoscopy and CT chest-soft tissue.

The patient was treated with right thoracotomy, excision of the fistulous tract and primary repair with pedicle subcostal muscle graft. Post-op recovery was uneventful. Patient discharged on $6^{\text {th }}$ post operative day with ICD.

INTRODUCTION: Benign bronchoesophageal fistulas (BEF) are uncommon and are usually identified in neonates. Adult bronchoesophageal fistulas are typically of acquired malignant, traumatic, or infectious origin.

The common embryonic origin of the respiratory tract and the oesophagus sometimes gives rise to anomalous communications such as tracheo-oesophageal fistula (TEF) and bronchooesophageal fistula (BEF). All patients with TEF associated with oesophageal atresia present in infancy [1]. In patients who have a congenital fistula without oesophageal atresia, symptoms are usually insidious in onset and may present in adult life [1-5]. Braimbridge and Keith [1] classified congenital broncho-oesophageal fistula (CBEF) into four types. The rarity of this condition and its insidious clinical course sometimes make the diagnosis difficult. If it is not suspected and left untreated, it may lead to fatal complications despite the benign nature of this anomaly [6].

One such case of congenital broncho-oesophageal fistula detected incidentally on upper GI endoscopy, presenting with recurrent upper respiratory infections and bronchiectasis, is being presented in this paper. The paper highlights the need for thorough evaluation for occult oesophageal respiratory fistula in any patient with chronic pulmonary suppuration of unknown etiology. Timely diagnosis and treatment will prevent serious complications and years of debilitating illness.

CASE REPORT: A 20-year-old student, a non-smoker, was referred to our OPD with a long-standing history of recurrent chest infections accompanied by a cough with expectoration of whitish sputum and sometimes hemoptysis. He also complains of coughing while eating or drinking occasionally. He had no history of choking, heartburn. He has been investigated for pulmonary tuberculosis few years back and his sputum cultures and PCR for tuberculosis were negative. An upper GI endoscopy demonstrated an opening on the right lateral wall of the oesophagus with mucus discharge at the 
distance of $29 \mathrm{~cm}$ from incisors. The patient was then posted for bronchoscopy which showed the communication between the right lower bronchus and the oesophagus.

On CT chest- soft tissue with oral and IV contrast, there were evidences of thin rent seen at right lateral wall mid esophagus at subcarinal region with opacification of right lower lobe cavity and bronchi with oral contrast suggestive of esophago-pulmonary, bronchial fistula. Also there were multilocular abscess in medial segment of right lower lobe with aspiration pneumonia, focal bronchiectasis with mucus plugs.

The remaining physical examination and laboratory data were within normal limits.

During the operation via right thoracotomy, it was observed that the oesophagus was filled with air by its distended appearance. Soon after dissecting the right lower bronchus, the fistulous communication between the anterior-lateral wall of the oesophagus and the right lower lobe bronchus was found. The fistula was $1 \mathrm{~cm}$ in length and $0.5 \mathrm{~cm}$ in diameter. There was no surrounding inflammatory reaction, tumor or enlarged lymph nodes. The fistula was excised and the oesophageal end repaired. And the closure was secured with the aid of subcostal muscular pedicle flap. The focal bronchiectasis and the multilocular abscess in the right lower, middle lobe were managed conservatively with antibiotics and expectorants.

Histopathological examination of the excised fistula revealed fistulous tract partly lined by fibrous tissue and partly lined by stratified squamous epithelium. Adjacent tissue showed focal round cell infiltration.

No evidence of granuloma and no evidence of malignancy were found in the excised sample.

DISCUSSION: A congenital fistula between the bronchus/trachea and the oesophagus results from failed tracheo-oesophageal separation in the early stage of embryonic development [7]. In adults, a fistula between the oesophagus and the respiratory tract is usually the result of malignant disease. Non-malignant oesophageal respiratory fistulas are relatively rare and may be congenital or acquired from trauma [8]

BEFs commonly communicate with the right lung, and fewer cases have been reported of left lung BEFs. This has been hypothesized to be due to a thinner muscle layer and lack of soft tissue envelope around the esophagus below the carina, causing a predilection for fistula formation in the right lung lobes [9]

BEF may, however, be silent for several decades for various reasons: (1) an occlusion of the opening by an oesophageal tissue fold or a 'flap valve'; (2) the presence of a membrane that subsequently ruptures; (3) the action of gravity (upward direction of the fistula from the oesophagus to the bronchi) preventing spillage of the oesophageal contents into the respiratory tree; (4) adaptation of patients to the minimal symptoms, and (5) spasm of the smooth muscle in the fistula wall [10,11,15]. However, none of these are well supported by pathologic or radiological findings.

CBEFs were classified by Braimbridge and Keith [1] into four types. Type I is associated with a wide necked congenital diverticulum of the oesophagus. Type II is the simplest and most common. A short tract runs directly from the oesophagus to the lobar or segmental bronchus. The patients presented in this report had type II BEF. Type III consists of a fistulous tract connecting the oesophagus to a cyst in the lobe, which, in time, communicate with the bronchus. In type IV the fistula runs into a sequestrated segment, which is recognized by the presence of a systemic arterial 


\section{CASE REPORT}

supply from the aorta. The sequestration connects with the oesophagus by one or more fistulous tracts.

A fistula may cause symptoms in childhood or may not appear until adult life $[1,6,7]$. A BEF is typically associated with repeated and persistent respiratory infections, which can lead to the development of bronchiectasis and coughing bouts when eating [11]. Hemoptysis is also seen occasionally. The presence of food in the sputum or choking on swallowing liquids may lead to the diagnosis of BEF. More uncommon symptoms include dysphasia, epigastric discomfort and reflux caused by the stomach filling with air on expiration. The common history and presentation in our patient as in most of the reported series were symptoms that began in childhood, with recurrent and persistent respiratory infections which led to the development of bronchiectasis, while the presenting symptom was hemoptysis.

The diagnosis can be reached using the oesophagoscopy and bronchoscopy as done in this case. CT chest-soft tissue with oral and IV contrast also helps in the diagnosis making. Oesophagography is considered to be more sensitive for the diagnosis of the condition. ${ }^{[2]}$

Division of the fistula and excision of any permanently damaged lung segment have been considered the method of choice in the treatment of this disease. Other treatment modalities cited in the literature were local application of sodium hydroxide, acetic acid and using a surgical stapler [12, 13].

Immediate surgical treatment is recommended for a finding of BEF despite its seemingly benign nature. Surgical treatment has the most favorable prognosis, but endoscopic occlusion with silver nitrate, biological glue, or a Celestin tube is also an option if a patient cannot tolerate a surgical procedure [14]

Herein, we reported case of CBEF presenting with bronchiectasis who were treated successfully with surgery.

\section{REFERENCES:}

1. Braimbridge MV, Keith HI: Oesophago-bronchial fistula in the adult. Thorax 1965; 20:226232.

2. Bekoe S, Magovern GJ, Liebler GA, Park SB, Cushing WJ: Congenital broncho-oesophageal fistula in the adult. Chest 1974;66:201-203.

3. Becker RM, Lesperance R, Despas P, Wilson JAS: Congenital oesophago-bronchial fistula in a 62-year-old woman. Chest 1976; 69:110-112.

4. Vaages S: Congenital oesophage-bronchial fistula in an adult. A case report. Scand J Thorac Cardiovasc Surg 1973; 7:91-94.

5. Azoulay D, Regnard JF, Magdeleinat P, Diamond T, Rojas-Miranda A, Levasseur P: Congenital respiratory-esophageal fistula in the adult. Report of nine cases and review of the literature. J Thorac Cardiovasc Surg 1992; 104:381-384.

6. 6 Risher WH, Arensman RM, Ochsner JL: Congenital bronchoesophageal fistula. Ann Thorac Surg 1990; 49:500-505.

7. Smith BD Jr, Mikaelian DO, Cohn HE: Congenital bronchoesophageal fistula in the adult. Ann Otol Rhinol Laryngol 1987; 96:65-67.

8. Gerzic Z, Rakic S, Randjelovic T: Acquired benign esophagorespiratory fistula. Report of consecutive cases. Ann Thorac Surg 1990; 50: 724-727. 


\section{CASE REPORT}

9. Shimada T, Abo S, Kitamura M, Hashimoto M, Shikama T, Kimura Y. [A case of congenital esophago-bronchial fistula communicated between esophageal diverticulum and left main bronchus in the adult--a review of 47 cases in the Japanese literature]. Nippon Kyobu Geka Gakkai Zasshi 1992; 40(11):2100-2106.

10. Smith DC: A congenital broncho-esophageal fistula presenting in adult life without pulmonary infection. Br J Surg 1970; 57:398-400.

11. Osinowo O, Harley HR, Janigan D: Congenital broncho-oesophageal fistula in the adult. Thorax 1983; 38:138-142.

12. Parry W, Juma A: Congenital bronchoesophageal fistula. Ann Thorac Surg 1991; 51:346-347.

13. Weissberg D, Kaufman M: Bronchoesophageal fistula in adults: Congenital or acquired? J Tho-rac Cardiovasc Surg 1990; 99:756-757.

14. Cossentino MJ, Ormseth EJ, Tavaf-Motamen H, Cheney CP. Congenital bronchoesophageal fistula in the adult: a case report. Am J Gastroenterol 2000; 95(8):2116-2118.

15. Ramo OJ, Salo JA, Mattila SP: Congenital bronchoesophageal fistula in the adult. Ann Thorac Surg 1995; 59:887-890.

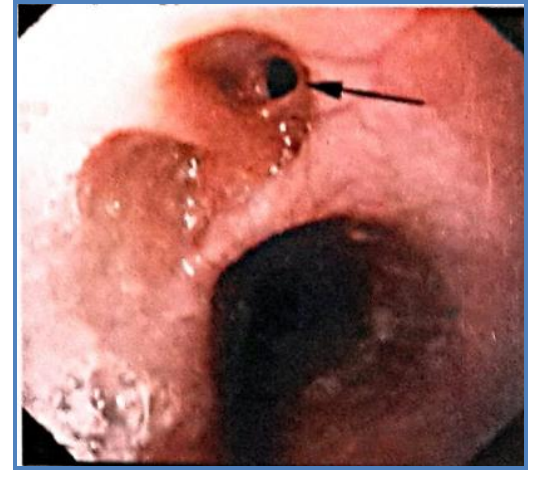

Fistula Tract

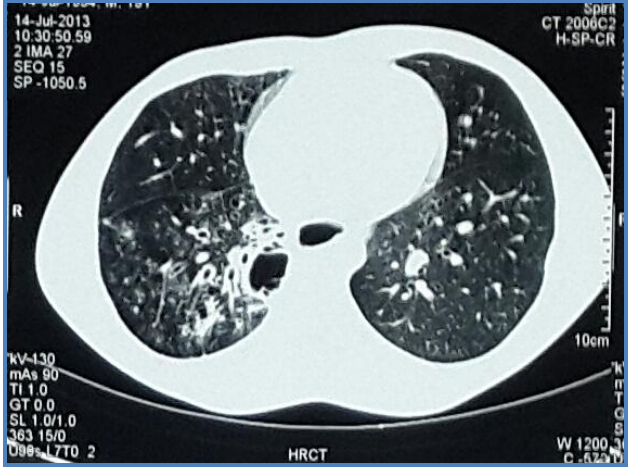

CT Scan Image bronchiectasis
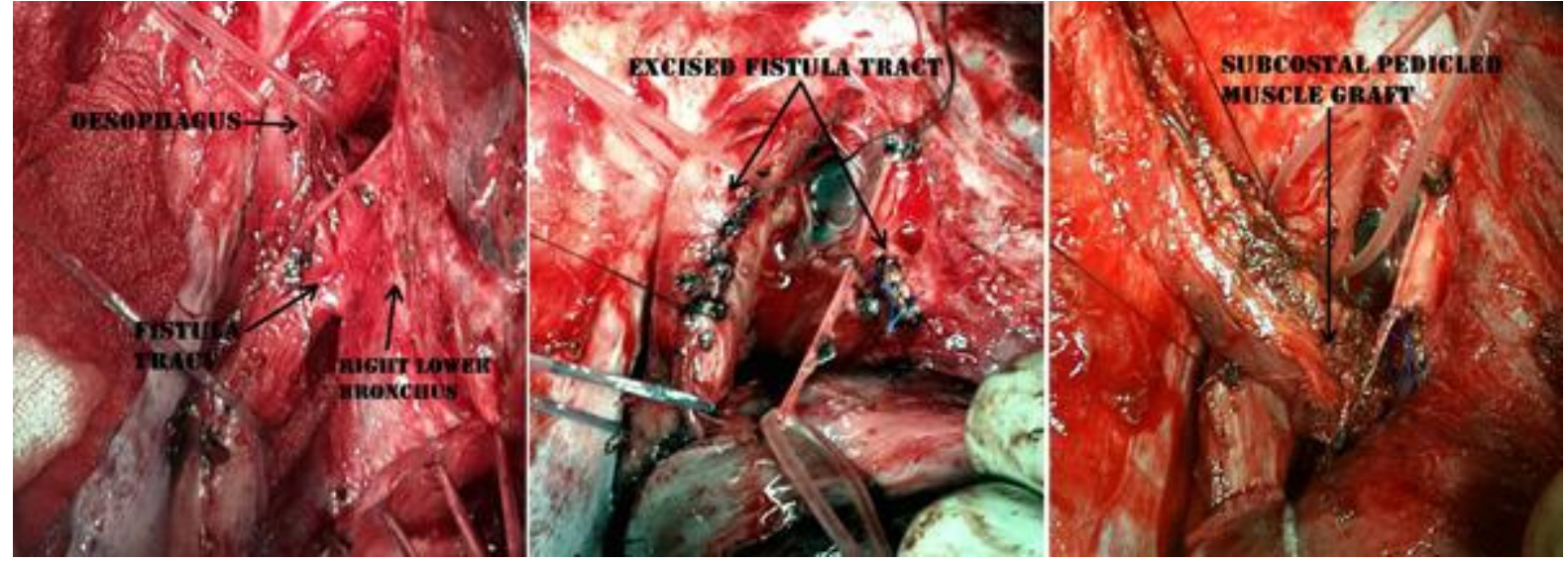


\section{AUTHORS:}

1. Narayan M.

2. Devershi Ajay Dilip

3. Chandankhede Abhijit Ravindra

\section{PARTICULARS OF CONTRIBUTORS:}

1. Consultant Surgeon, Department of General Surgery, Kerudi Hospital and Research Centre, Bagalkot, Karnataka.

2. PG Resident, Department of General Surgery, Kerudi Hospital and Research Centre, Bagalkot, Karnataka.

3. PG Resident, Department of General Surgery, Kerudi Hospital and Research Centre, Bagalkot, Karnataka.

\section{NAME ADRRESS EMAIL ID OF THE}

\section{CORRESPONDING AUTHOR:}

Dr. Devershi Ajay Dilip,

Kerudi Hospital and Research Centre,

Extension Area, Bagalkot,

Karnataka.

Email - dr.ajax.dd@gmail.com

Date of Submission: 03/10/2013.

Date of Peer Review: 04/10/2013.

Date of Acceptance: 07/10/2013.

Date of Publishing: 18/10/2013 